advice, has the courage to tell the people that they must eat what is good for them and not what they individually fancy. Perhaps our national habits are about to be changed under scientific guidance. The work has been done in many laboratories; its interpretation has been the subject of much discussion and often controversy. Such problems have many angles, wide reading is required to appreciate them, and, since the number of papers has increased beyond our powers of study, summaries have become essential.

Murray Luck and his helpers realize that the pursuit of learning is in peril : it is for them in the Pacific and us in beleaguered Britain to prevent the eclipse.

Comment in detail on such a wide subject is more than usually difficult. It is of interest to read the statement that a protein is now being regarded by many workers as a pattern rather than as a thing -a molecule of definite composition but of dubious size. Analytical work is now once more considered of importance in establishing protein structure. The proteinase enzymes are regarded as consisting of two proteins at once.

Though viruses were discovered in 1892 it was not until 1935 that a tangible characteristic material carrying virus activity became available for biochemical study. They now form a fashionable subject for intense research, and a large number of general reviews, five books, and a new journal dealing with them have appeared during 1939. Another subject which is largely novel is insect biochemistry: here the biochemist is beginning to encounter many surprising phenomena.

The bulk of the essays bear well-known American names, but there are several British contributors, notably Heilbron and Jones, Channon, Raistrick, J. A. B. Smith, Dodds and Dickens.

E. F. Armstrong.

\title{
INDIAN SPOROZOA
}

The Fauna of British India, including Ceylon and Burma

Protozoa: Sporozoa. By Dr. B. L. Bhatia. Pp. $\mathrm{xx}+498+2$ plates. (London: Taylor and Francis, Ltd., 1938.) $30 s$.

$\mathrm{T}$ HIS volume, dealing with the Sporozoa, is the author's second publication on the Protozoa in "The Fauna of British India", and follows the plan adopted in the preceding volume on the Ciliophora. Though a number of text-books on general protozoology have appeared in the last decade the treatment of the Sporozoa in them is very inadequate, while the more specialized publications devoted to the parasitic protozoa are already out of date. Dr. Bhatia has rendered a useful service by producing a comprehensive and modern work on the Sporozoa which, though limited to the description of those species which have been recorded from India and adjoining countries, will be of undoubted value to zoologists in all other parts of the world, since most of the genera belonging to this group have a cosmopolitan distribution. With the help of the keys provided, it should be possible to identify the genus of almost any sporozoon.

In the introduction the author reviews the position of the Sporozoa in the animal kingdom, their structure, phylogeny and classification. Lists are given of the parasites and their hosts, and vice versa, and there is a useful section on technique, dealing with the methods for the examination and study of these parasites. The greater part of the book is devoted to a systematic account of the Sporozoa. The description of each subdivision is accompanied by dichotomous keys for the identification of the lower units, down to genera and species. A separate description is given of each species recorded from India (total 320), usually with illustrations, and including the relevant references and synonyms. The classification adopted can be seen at a glance in the "Systematic Index" which contains the names of all the organisms recorded in the book, arranged in their systematic order. There is also a useful glossary of technical terms and an extensive bibliography occupying more than one hundred pages. The monograph is abundantly illustrated by text figures and by two coloured plates depicting human and simian malarial parasites.

There are several instances in which the nomenclature differs from that accepted by the majority of protozoologists (for example, Laverania malarice for the parasite of malignant tertian malaria), but this is a controversial subject where difference of opinion is justifiable. Dr. Bhatia can be congratulated on the production of a book which will be of great assistance to zoologists-especially parasitologists and protozoologists, including medical and veterinary workers-in need of an authoritative and up-to-date guide to the systematics of the Sporozoa. 